\title{
Effects of Different Bleaching Agents on the Surface Topography and the Microhardness of Artificial Carious Lesions
}

\author{
Rasha Owda ${ }^{1, \odot}$ Hande Sar Sancakli \\ ${ }^{1}$ Department of Restorative Dentistry, Faculty of Dentistry, Biruni \\ University, Istanbul, Turkey \\ ${ }^{2}$ Department of Restorative Dentistry, Faculty of Dentistry, Istanbul \\ University, Istanbul, Turkey
}

Address for correspondence Rasha Owda, DDS, PhD, Department of Restorative Dentistry, Faculty of Dentistry, Biruni University, Zeytinburnu, TR-34010 Istanbul, Turkey (e-mail: rowda@biruni.edu.tr).

Eur J Dent 2021;15:687-693.

\begin{abstract}
Keywords

- in-office bleaching

- home bleaching

- artificial caries lesions

- microhardness

- SEM

Objectives The aim of this study was to evaluate the effects of in-office and at-home bleaching agent applications on the surface topography and microhardness of artificially demineralized enamel.

Materials and Methods A total of 224 enamel specimens were prepared using bovine sound central incisors. $4 \mathrm{~mm} \times 4 \mathrm{~mm}$ enamel windows were exposed on the buccal surfaces covering the remaining surface with nail varnish. Samples were immersed in a demineralizing solution for 16 hours to produce artificial caries lesions, then divided into four groups according to the bleaching agent's type and concentration. Group I; in-office bleaching 35\% hydrogen peroxide (HP) (Whiteness HP Maxx; FGM, Brazil), Group II and Group III at-home bleaching 16 and 22\% carbamide peroxide $\mathrm{CP}$, respectively (Whiteness Perfect). Group IV; control (not bleached). The microhardness Vickers hardness number (VHN) was measured at the baseline, after demineralization, and after bleaching consequently. The micro-surface changes of the enamel surface after demineralization and bleaching were evaluated by scanning electron microscope (SEM).

Statistical Analysis Data were evaluated by the one-way analysis of variance (ANOVA) test followed by Post Hoc Tukey's and Fisher's least significant difference. Tow- sided $p$-values were considered statistically significant at $p \leq 0.05$.

Results A significant reduction was noticed in the enamel microhardness after demineralization $p<0.05$. However, there is no statistically significant difference between the mean VHN of the demineralized and bleached enamel $(p>0.001)$. SEM images showed significant changes on the surface of the demineralized enamel after bleaching (pattern type III).

Conclusions The low and high concentrations of HP and CP bleaching agents increased the demineralization severity of artificial caries lesions without significantly altering their microhardness values.
\end{abstract}

published online August 24, 2021
DOI https://doi.org/

$10.1055 / \mathrm{s}-0041-1728237$ ISSN $1305-7456$
(C) 2021. European Journal of Dentistry.

This is an open access article published by Thieme under the terms of the Creative Commons Attribution-NonDerivative-NonCommercial-License, permitting copying and reproduction so long as the original work is given appropriate credit. Contents may not be used for commercial purposes, or adapted, remixed, transformed or built upon. (https://creativecommons.org/licenses/by-nc-nd/4.0/).

Thieme Medical and Scientific Publishers Pvt. Ltd. A-12, 2nd Floor, Sector 2, Noida-201301 UP, India 


\section{Introduction}

Early enamel caries lesions on the labial surface of anterior teeth are considered an oral health and aesthetic problem. These lesions are mostly seen following fixed orthodontic treatment or as chronic lesions seen in high caries risk patients. The treatment decision and the appropriate clinical management of these lesions depend on caries activity assessment mainly and many other factors such as cavitation, cleansability, caries risk, behavioral adherence, age, and dentition. ${ }^{1,2}$ Active early enamel caries lesions are characterized by subsurface demineralization at 200 to $300 \mu \mathrm{m}$ depth, and enamel surface roughness with loss of shine. Regarding the minimal intervention dentistry the first strategy of treatment focuses on diet management and oral hygiene, while the second strategy focuses on reversing the lesions by applying remineralizing agents such as fluorides and phosphopeptide compounds. Both these strategies aim to prevent the caries lesions progression and to improve their mechanical properties. However, the third strategy aims to mask or enhance the lesions aesthetic appearance by dental bleaching, microabrasion, or the recently developed resin infiltration technique. ${ }^{2-5}$ On the other hand, the inactive early enamel carious lesions characterized by the intact, remineralized smooth surfaces and high mechanical properties are frequently associated with discolorations. This unesthetic appearance is commonly managed by dental bleaching or microabrasion technique. ${ }^{1,6}$

Dental bleaching is an oxidation process, the bleaching agents generate free radicals that penetrate through enamel into the dentin and convert the high molecular chromophores into smaller molecules leading to whiter appearance. ${ }^{78}$ Dental bleaching procedures are applied using two techniques; in-office bleaching and home bleaching using various concentrations of hydrogen peroxide (HP) and carbamide peroxide gels $(\mathrm{CP}){ }^{9}{ }^{9}$

Since bleaching agents may change the value of the enamel visibly, many studies showed a satisfactory camouflage effect of bleaching agents on post orthodontic white spot lesions and artificial caries lesions as well. ${ }^{10-13}$. However, the application of bleaching agents to an already demineralized enamel tissue is a controversial issue for researchers and dental practitioners. Some studies reported a significant reduction in the microhardness of demineralized enamel lesions after bleaching, while others demonstrated no significant effect or even an increase in the microhardness values. But most of these studies were conducted under in vitro conditions with different study designs. and low concentrations of bleaching agents were used, claiming that high concentration may cause further demineralization and compromise the mechanical properties of these mineral-depleted lesions. . $^{514-17}$

To the best of our knowledge, the effect of different concentrations of both in-office and home bleaching agents on the microhardness and surface morphology of the demineralized enamel lesions has not been published. Therefore, in the present in vitro study we aimed to evaluate both the high and low concentrations of HP and CP bleaching agents effects effect on the microhardness of artificially demineralized enamel under intra-oral simulating conditions. Also, we aimed to qualitatively evaluate the enamel surface morphological micro-changes of the demineralized enamel after bleaching. The null hypotheses are: (1) bleaching agents have no significant effect on the microhardness of the demineralized enamel lesions, and (2) the the bleaching agents type and concentration have no impact on the surface morphology.

\section{Materials and Methods}

Ethical approval of this study was obtained from Istanbul University Animal Experiments Local Ethics Committee under the number of 2016/08. The bovine teeth were obtained from animals cut independently from this research.

\section{Specimens Preparation}

A total of 224 sound bovine permanent incisors were stored in $0.1 \%$ Thymol solution for 1 week before processing to cut enamel slabs $5 \times 4 \times 4 \mathrm{~mm}$ by a Precision Saw (IsoMet 1000, Buehler, Lake Bluff, Illinois, United States) under continuous water irrigation. The prepared enamel specimens were embedded in methyl methacrylate resin blocks. The surface of each specimen was grounded and polished using waterproof silicon carbide papers (1,200-2,400 grit; Allied High-Tech Product Inc, Compton, California, United States) attached to the polishing machine (Buehler MetaServ 250, Düsseldorf, Germany). Subsequently, acid-resistant nail varnish was used to create enamel windows $4 \mathrm{~mm} \times 4 \mathrm{~mm}$.

\section{Artificial Caries Lesions Formation}

In the present study, the chemical protocol was used to create subsurface carious lesions artificially because it is a rapid, reliable, and low-costing test. The demineralization solution used was composed of $50 \mathrm{mM}$ acetate buffer solution; itcontains $1.28 \mathrm{mMCa}\left(\mathrm{NO}_{3}\right)_{2} \times 4 \mathrm{H}_{2} \mathrm{O}, 0.74 \mathrm{mMNaH}_{2} \mathrm{PO}_{4} \times 2 \mathrm{H}_{2} \mathrm{O}$, and $0.03 \mathrm{ppm} \mathrm{F}$ at $\mathrm{pH} 5.0$ for 16 hours (Sigma Aldrich, Steinheim, Germany). ${ }^{18}$ Each sample was immersed in $20 \mathrm{~mL}$ of the solution at $37^{\circ} \mathrm{C}$. After the demineralization process, the specimens were washed thoroughly with distilled water and air-dried using the triple syringe.

\section{Experimental Design}

The demineralized enamel specimens were divided according to the bleaching agents type and concentration $(n=56)$. Group I: office bleaching 35\% hydrogen peroxide (Whiteness HP Maxx, FGM Dental Products, Joinville, Santa Catarina, Brazil); Group II: home bleaching 16\% carbamide peroxide (Whiteness Perfect, FGM Dental Products, Joinville, Santa Catarina, Brazil) and Group III: home bleaching 22\% carbamide peroxide (Whiteness Perfect; Group IV: nonbleached

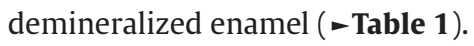

\section{Bleaching \\ Group I (In-office Bleaching 35\% HP)}

The bovine enamel samples with artificial carious lesions in GI were treated by in-office bleaching technique. 35\% HP bleaching gel (Whiteness HP Maxx, FGM Dental Products, 
Table 1 The materials used in the study

\begin{tabular}{|l|l|l|l|}
\hline Material & Composition & Batch number & Manufacture \\
\hline Whiteness HP Maxx 35\% & $\begin{array}{l}\text { 35\% hydrogen peroxide, dye, glycol, } \\
\text { thickening agent, and distilled water }\end{array}$ & 110116 & FGM Dental Products, Joinville, Brazil \\
\hline Whiteness Perfect 16\% & $\begin{array}{l}16 \% \text { carbamide peroxide, water, potas- } \\
\text { sium nitrate, sodium fluoride, and glycol. }\end{array}$ & 080316 & FGM Dental Products, Joinville, Brazil \\
\hline Whiteness Perfect 22\% & $\begin{array}{l}\text { 22\% carbamide peroxide, water, potas- } \\
\text { sium nitrate, sodium fluoride, and glycol }\end{array}$ & 120116 & FGM Dental Products, Joinville, Brazil \\
\hline
\end{tabular}

Joinville, Santa Catarina, Brazil) was applied on the demineralized enamel surface in a 2-mm thickness layer. To mimic the clinical applications the bleaching gel was applied twice, each session lasts for 20 minutes. bleaching gel was activated by LED light curing unit until the color has changed. At the end of each session the specimens were thoroughly rinsed with distilled water for 30 seconds before being immersed in an artificial saliva solution for 14 days.

\section{Group II (Home Bleaching 16\% CP)}

The enamel samples in this group were treated by at-home bleaching technique for 14 days to imitate the clinical indications. 16\% CP (Whiteness Perfect) was applied on the demineralized enamel samples for $4 \mathrm{~h} /$ day. Approximately 1-2 mm thickness layer of the bleaching gel was applied in the acrylic bleaching trays and adapted well over the models. During bleaching period, the models were kept in a wet enviornment at $37^{\circ} \mathrm{C}$ in the incubator. After each bleaching session, the specimens were washed, dried, and stored in the artificial saliva solution until the next day.

\section{Group III (Home Bleaching 22\% CP)}

For this group, the same methodology applied in GII was followed. 22\% CP (Whiteness Perfect) bleaching gel was used in the trays for $1 \mathrm{~h}$ /day for a period of 14 days. After each bleaching session, the specimens were washed, dried, and stored in an artificial saliva solution until the next session.

\section{Artificial Saliva Preparation}

To simulate the oral environment and standardize the study conditions in our protocol, all specimens were immersed in the artificial saliva solution at $37^{\circ} \mathrm{C}$ in the incubator for 14 days. The samples were stored in distilled water during the microhardness test. The prepared artificial saliva solution contains $42 \mathrm{mMol} \mathrm{C}_{8} \mathrm{H}_{16} \mathrm{NaO}_{8}$, $4.6 \mathrm{mMol} \mathrm{HK}_{2} \mathrm{O}_{4} \mathrm{P}, 16 \mathrm{mMol}$ $\mathrm{NaCl}, 564 \mu \mathrm{Mol} \mathrm{Cl}{ }_{2} \mathrm{Mg}$, and $29 \mu \mathrm{g} \mathrm{C}_{14} \mathrm{H}_{18} \mathrm{~N}_{2} \mathrm{O}_{5}$ at $\mathrm{pH}=7 .{ }^{19}$

\section{Enamel Microhardness Measurement (Vickers Test)}

The enamel surface microhardness was measured by the Vickers microhardness (Innovatest, Manual Impression XT Hardness Testing Instrument, Software Version 1.07, Hollanda). The elongated pyramid indentor with a specific constant load of $300 \mathrm{~g}$ was applied over the enamel surface for 15 seconds. ${ }^{20}$ The microhardness measurements were calculated for each sample at sound bovine enamel (baseline), artificial caries lesion (demineralized), and after bleaching successively. The built-in scaled microscope measured the indentation's diagonal length, and Vickers test values were calculated. Three indentations were placed in the enamel surface and the distance between the indentations was approximately $50 \mu \mathrm{m}$. The average value was counted for each specimen.

\section{Scanning Electron Microscope}

The enamel surface microtopographic features and changes during the current study were analyzed by the scanning electron microscope (Quanta FEG 450 SEM; FEG company, Hillsboro, Oregon, United States). Three samples from each group were analyzed at the sound bovine enamel (baseline), artificial caries (demineralized), and after bleaching. The randomly chosen samples were dehydrated using the direct technique recommended by Janda et al. ${ }^{21}$ First, all specimens were immersed in 50,60, 70, and 99\% ethyl alcohol solutions subsequently for 20 minutes, then in 99\% ethyl alcohol for 1 hour. ${ }^{22}$ The presence of a thick layer of dentin underlying the enamel made the samples more difficult to dry out. Therefore, samples were again immersed in 99\% ethyl alcohol for 24 hours. After that, gold sputtering at 100 Angstrom $\left(A^{\circ}\right)$ thickness was performed and the samples were scanned at $2,000 X$ to $20,000 X$ magnification. Scanning electron microscope (SEM) images were evaluated qualitatively.

\section{Statistical Analysis}

Data were analyzed by the Statistical Package for the Social Sciences (SPSS 21.0, IBM Corporation, Armonk, New York, United States) software program. Mean and standard deviation (SD) were calculated for continuous variables. The normality of the variables was analyzed using the Shapiro-Wilk test. For the parametric groups, the one-way analysis of variance (ANOVA) test followed by Post Hoc Tukey's and Fisher's least significant difference (LSD). The variables distributed categorically or discretely were analyzed by using Wilcoxon for the Paired test and Kruskal-Wallis test for multiple groups. Tow-sided $p$-values were considered statistically significant at $p \leq 0.05$.

\section{Results}

\section{Enamel Microhardness Test}

- Table 2 shows the mean and SD of Vickers microhardness values. All study groups showed a statistically significant reduction in the mean microhardness values VHN of the sound bovine enamel demineralization and artificial caries creation $(p<0.05)$. The evaluation of microhardness revealed a reduction of $78 \%$ for GI, $71 \%$ for GII, $76 \%$ for GIII, and $75 \%$ for the control group. However, no significant difference had been noticed between the microhardness value of the 
Table 2 The mean and standard deviation (mean \pm SD) of the Vickers microhardness values of all groups at the different stages (sound enamel, demineralized enamel, and bleached enamel)

\begin{tabular}{|l|l|l|l|l|}
\hline Group & $\begin{array}{l}\text { Sound enamel } \\
\text { Mean } \pm \text { SD }\end{array}$ & $\begin{array}{l}\text { Demineralized enamel } \\
\text { Mean } \pm \text { SD }\end{array}$ & $\begin{array}{l}\text { Bleached enamel } \\
\text { Mean } \pm \text { SD }\end{array}$ \\
\hline $\mathrm{GI}=35 \% \mathrm{H}_{2} \mathrm{O}_{2}$ & $n=56$ & $304.63 \pm 34.19$ & $68.39 \pm 29.12$ & $77.42 \pm 31.07$ \\
\hline $\mathrm{GII}=16 \% \mathrm{CP}$ & $n=56$ & $312.67 \pm 38.84$ & $73.85 \pm 29.02$ & $74.82 \pm 29.31$ \\
\hline $\mathrm{GIII}=22 \% \mathrm{CP}$ & $n=56$ & $316.84 \pm 35.96$ & $89.73 \pm 23.91$ & $91.57 \pm 30.75$ \\
\hline $\mathrm{GIV}=$ control group & $n=56$ & $313.92 \pm 36.77$ & $77.54 \pm 39.49$ & 0.092 \\
\hline $\begin{array}{l}\text { p-Value between } \\
\text { groups }\end{array}$ & 0.633 & 0.072 & \\
\hline
\end{tabular}

Abbreviations: CP, carbamide peroxide; GI, group I; Gll, group II; GIII, group III; GIV, group IV; $\mathrm{H}_{2} \mathrm{O}_{2}$, hydrogen peroxide; SD, standard deviation. Note: One-way ANOVA $p<0.05$ significant.

control group and the demineralized enamel after bleaching $(p>0.05)$. On the contrary, a slight increase in the microhardness values had been noticed after bleaching. The increasing percentage of the microhardness values was $13 \%$ for GI, $6 \%$ for GII, and $2 \%$ for GIII. GI presented the highest microhardness increase with the statistically non-significant difference compared with GII and GIII $(p>0.05)$.

\section{SEM Analysis}

The enamel surface microchanges representative micrographs are illustrated in $\boldsymbol{- F i g}$. 1 . The intact bovine enamel specimens viewed under 2,000X magnification revealed homogeneous and slightly rough surface integrity following the enamel natural crystal structure and the study methodology (- Fig. 1A). Considering the enamel surface quantitative evaluations after demineralization, SEM images viewed at 20,000X magnification presented a rougher surface and enlargement in the interprismatic area along with the dissolution of the peripheries of the prism sheath (type III enamel etching pattern; - Fig. 1B). However, after bleaching, the SEM images under 20,000X magnification demonstrated dissolution in the periphery of the prism sheath, rough surfaces, and a wide interfractional area, representing the same etching pattern of demineralized enamel but in a more prominent manner (-Figs. 1C-E). The high and low concentrations of the bleaching agents showed the same demineralization pattern.

\section{Discussion}

Bleaching early enamel caries lesions manifested as WSLs is broadly evaluated in research, ${ }^{5,10-17}$ but the dilemma about its efficacy and safety is still present. The surface microhardness which represents the mechanical properties of the dental hard tissues and their mineral content, ${ }^{15}$ is the most commonly used test. Since detecting a square surface reveals more clear traces, Vickers test was chosen instead of the Knoop test in our protocol to measure the microhardness. ${ }^{23}$ In the present study, the effects of two types of bleaching agents applied in different concentrations and techniques on the microhardness of artificial caries lesions were evaluated.

The bleaching agents used in the this study are; in-office bleaching 35\% HP and at-home bleaching 16\% CP and 22\%
$\mathrm{CP}$. The chosen products have a neutral $\mathrm{pH}$ value which is necessary for the whitening safety. Home bleaching products contain remineralizing agents which are missing in the office bleaching agents. Both types showed no significant effect on the microhardness. However, a slight increase in the mean VNH had been investigated in all bleaching groups (GI, GII and GIII) with no significant difference between study groups. Thus, our first hypothesis was accepted.

These findings agree with many studies providing evidence that bleaching could camouflage WSLs without affecting their mineral content and microhardness values..$^{16}$ Furthermore, significant remineralization and improved mineral content were obtained especially when fluoridated bleaching gel was applied. ${ }^{15,24}$ These outcomes contrast with results showing significant microhardness reduction obtained following at-home and laser-assisted office bleaching of WSLs. ${ }^{25}$

The slight increase of the microhardness of artificial caries lesions after bleaching in the present study is thought to be an accumulative result of many factors, including the bleaching agent's content, $\mathrm{pH}$ value, and study design. The nonsignificant increase in the microhardness had been noticed in all study groups. It is suggested that in GII and GIII (16 and 22\% Whiteness Perfect), the potassium nitrate and sodium fluoride content of the bleaching gels could have attributed to microhardness increase. It was already demonstrated that adding remineralizing agents such as CPP-ACP paste, fluoride, and nano-biomaterials to bleaching gels enhances the mineral deposition, induces fluoride acquisition and prevents irreversible changes on enamel without altering the whitening efficacy. ${ }^{16,24,26-30}$ While, in GI (35\% HP Whiteness HP Maxx) the microhardness increase is thought to be related to the short application time of the bleaching gel and the early contact with saliva. Artificial saliva, following the literature, can boost the remineralization and increase enamel microhardness subsequently. ${ }^{15,25,31}$ Another reason to support these findings is supposed to be the neutral $\mathrm{pH}$ value of the bleaching gels. The literature had shown less demineralization, microhardness reduction, and enamel surface roughness in neutral $\mathrm{pH}$ agents compared with those with lower $\mathrm{pH}$ values. ${ }^{16,27}$

The qualitative evaluation of SEM images revealed surface porosities, roughness, dissolution in the prism sheath 

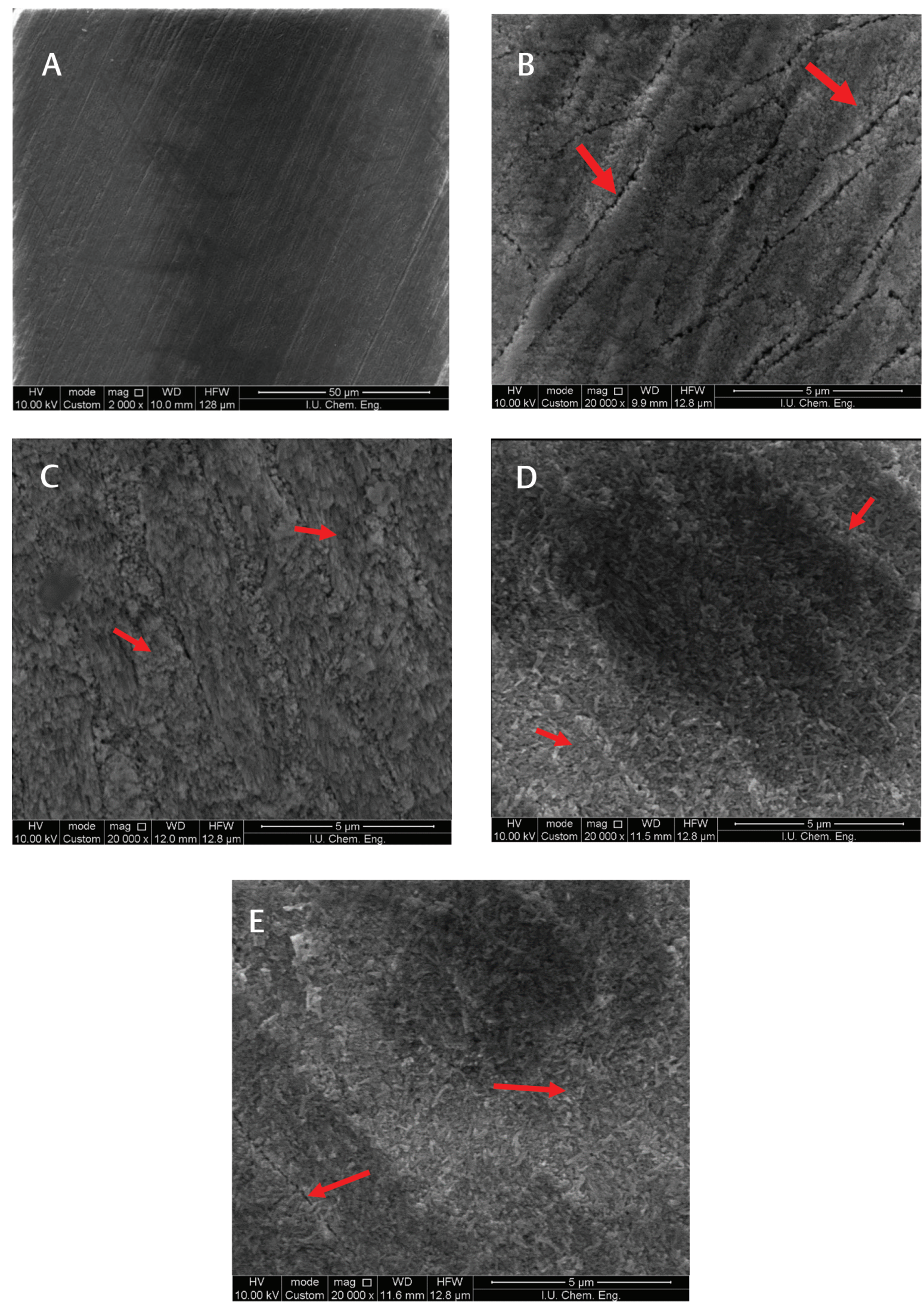

Fig. 1 SEM images analysis. (A) Sound enamel, a homogeneous and slightly rough surface is observed under 2000X magnification. (B) Demineralized enamel; the porous surface represents partial dissolution of the aprismatic layer and enlargement of the interprismatic spaces. Slight dissolution of the prismatic core is observed under $(20,000 \mathrm{X})$ magnification. (C) Gl; substantial dissolution of the aprismatic layer mainly in the interprismatic spaces with moderate dissolutions of prismatic core (20,000X). (D) Gll; considerable dissolution of the aprismatic layer associated with increased porosity and moderate dissolution of the interprismatic area (20,000X). (E) GIII; mild dissolution of prismatic core and peripheries areas with enlargement of the interprismatic spaces (20,000X). SEM, scanning electron microscope. 
periphery, and wide interprismatic area after enamel demineralization. More porous surfaces, wider interprismatic area, and further dissolutions in the aprismatic surfaces with grooves are identified after the bleaching regimen. These findings display that HP and CP bleaching agents in different concentrations showed a similar demineralization pattern to the artificial caries (type III) but in a more prominent form. Thus, the second hypothesis was accepted. These results agree with the previous study presenting enamel demineralization up to $50-\mu \mathrm{m}$ depth after $10 \%$ CP bleaching gel application evaluated by a computerized tomography technique. ${ }^{32}$ However, it contrasts with CLSM study which reported that the increase in the demineralization depth noticed after bleaching was not significant. ${ }^{14}$

The revealed structural changes of enamel and caries susceptibility associated with bleaching in some studies were considered clinically negligible, ${ }^{15,33}$ while, in other studies it is thought to be a consequence of saliva remineralization property. ${ }^{34,35}$ In the present study, the use of artificial saliva solutions during and after bleaching might promoted mineral deposition and subsequently increased the demineralized enamel microhardness after bleaching without altering the surface characteristics.

The clinical bleaching outcomes depend on several factors such as the bleaching agent type, concentration, content, $\mathrm{pH}$ value, and the application technique. In the case of in vitro studies, the enamel characteristics and structural discrepancies between the natural and artificially prepared lesions may also contribute to the variation of the results. Accordingly, in vitro studies limitations make these results confined, and emphasize the need of more in vivo and in situ studies.

Within the limitations of the present study, low and high concentrations of HP and CP bleaching agents can be used safely for whitening early enamel caries lesions without further compromisation of their mechanical and surface properties. However, taking into considerations the hypomineralization nature and low mechanical properties of these lesions compared to sound enamel, various contemporary minimally invasive treatment options combined with bleaching can be recommended to enhance the microhardness recovery and prevent further demineralization.

\section{Funding}

The present study was funded by the Research Fund of Istanbul University (project No. 21128) and FGM Dental Products Dental Group, Joinville, Santa Catarina, Brazil.

\section{Conflict of Interest}

None declared.

\section{References}

1 Schwendicke F, Splieth C, Breschi L, et al. When to intervene in the caries process? An expert Delphi consensus statement. Clin Oral Investig 2019;23(10):3691-3703 doi:10.1007/ s00784-019-03058-w

2 Drancourt N, Roger-Leroi V, Martignon S, Jablonski-Momeni A, Pitts N, Doméjean S. Carious lesion activity assessment in clinical practice: a systematic review. Clin Oral Investig 2019;23(4):1513-1524 doi:10.1007/s00784-019-02839-7

$3 \mathrm{Hu} \mathrm{H}$, Feng C, Jiang Z, et al. Effectiveness of remineralising agents in prevention and treatment of orthodontically induced white spot lesions: a protocol for a systematic review incorporating network meta-analysis. Syst Rev 2019;8(1):339

4 Sonesson M, Bergstrand F, Gizani S, Twetman S. Management of post-orthodontic white spot lesions: an updated systematic review. Eur J Orthod 2017;39(2):116-121 doi:10.1093/ejo/cjw023

5 Gizani S, Papadimitriou A, Twetman S. Is bleaching effective in managing post-orthodontic white-spot lesions? Syst Rev 2020; 18(1):1-10

6 Machiulskiene V, Campus G, Carvalho JC, et al. Terminology of dental caries and dental caries management: consensus report of a workshop organized by ORCA and Cariology Research Group of IADR. Caries Res 2020;54(1):7-14 doi:10.1159/000503309

7 Bersezio C, Estay J, Jorquera G, et al. Effectiveness of dental bleaching with $37.5 \%$ and $6 \%$ hydrogen peroxide and its effect on quality of life. Oper Dent 2019;44(2):146-155

8 Alqahtani MQ. Tooth-bleaching procedures and their controversial effects: a literature review. Saudi Dent J 2014;26(2): 33-46

9 Paula ABP, Fernandes AR, Coelho AS, et al. Therapies for white spot lesions-a systematic review. J Evid Based Dent Pract 2017; 17(1):23-38

10 Knösel M, Attin R, Becker K, Attin T. External bleaching effect on the color and luminosity of inactive white-spot lesions after fixed orthodontic appliances. Angle Orthod 2007;77(4): 646-652

11 Al-Angari SS, Hara AT. A conservative approach to esthetically treat stained arrested caries lesions. Quintessence Int 2016;47(6):499-504. Doi: 10.3290/j.qi.a36010

12 Kwon SR, Cortez E, Wang M, Jagwani M, Oyoyo U, Li Y. Systematic review of in vitro studies evaluating tooth bleaching efficacy. Am J Dent 2020;33(1):17-24

13 Kothari S, Gray AR, Lyons K, Tan XW, Brunton PA. Vital bleaching and oral-health-related quality of life in adults: A systematic review and meta-analysis. J Dent 2019;84:22-29. Doi:10.1016/j.jdent.2019.03.007

14 Berger SB, Pavan S, Dos Santos PH, Giannini M, Bedran-Russo AKB. Effect of bleaching on sound enamel and with early artificial caries lesions using confocal laser microscopy. Braz Dent J 2012;23(2):110-115

15 Pinto CF, Paes Leme AF, Cavalli V, Giannini M. Effect of $10 \%$ carbamide peroxide bleaching on sound and artificial enamel carious lesions. Braz Dent J 2009;20(1):48-53 doi:10.1590/ s0103-64402009000100008

16 Kim Y, Son HH, Yi K, Ahn JS, Chang J. Bleaching effects on color, chemical, and mechanical properties of white spot lesions. Oper Dent 2016;41(3):318-326

17 Omar F, Ab-Ghani Z, Rahman NA, Halim MS. Nonprescription bleaching versus home bleaching with professional prescriptions: which one is safer? A comprehensive review of color changes and their side effects on human enamel. Eur J Dent 2019;13(4):589-598

18 Borges A, Caneppele T, Luz M, Pucci C, Torres C. Color stability of resin used for caries infiltration after exposure to different staining solutions. Oper Dent 2014;39(4):433-440

19 DA Silva MA, Vitti RP, Sinhoreti MA, Consani RL, Silva-Júnior JG, Tonholo J. Effect of alcoholic beverages on surface roughness and microhardness of dental composites. Dent Mater J 2016;35(4):621-626

20 Taher NM, Alkhamis HA, Dowaidi SM. The influence of resin infiltration system on enamel microhardness and surface roughness: an in vitro study. Saudi Dent J 2012;24(2):79-84 
21 Janda R. Preparation of extracted natural human teeth for SEM investigations. Biomaterials 1995;16(3):209-217 doi:10.1016/0142-9612(95)92119-q

22 Miranda CB, Pagani C, Benetti AR, Matuda FdaS. Evaluation of the bleached human enamel by scanning electron microscopy. J Appl Oral Sci 2005;13(2):204-211

23 Chuenarrom C, Benjakul P, Daosodsai P. Effect of indentation load and time on knoop and vickers microhardness tests for enamel and dentin. Mater Res 2009;12(4):473-476

24 Bollineni S, Janga RK, Venugopal L, Reddy IR, Babu PR, Kumar SS. Role of fluoridated carbamide peroxide whitening gel in the remineralization of demineralized enamel: An in vitro study. J Int Soc Prev Community Dent 2014;4(2):117-121 doi:10.4103/2231-0762.137638

25 Ghanbarzadeh M, Ahrari F, Akbari M, Hamzei H. Microhardness of demineralized enamel following home bleaching and laserassisted in office bleaching.JClinExpDent2015;7(3):e405-e409

26 Gladwell J, Simmons D, Wright JT. Remineralization potential of a fluoridated carbamide peroxide whitening gel. J Esthet Restor Dent 2006;18(4):206-212, discussion 212-213

27 Cavalli V, Rosa DAD, Silva DPD, et al. Effects of experimental bleaching agents on the mineral content of sound and demineralized enamels. J Appl Oral Sci 2018;26:e20170589 doi:10.1590/1678-7757-2017-0589
28 Chen HP, Chang CH, Liu JK, Chuang SF, Yang JY. Effect of fluoride containing bleaching agents on enamel surface properties. J Dent 2008;36(9):718-725 doi:10.1016/j.jdent.2008.05.003

29 Khoroushi M, Mazaheri H, Saneie T, Samimi P. Fracture toughness of bleached enamel: effect of applying three different nanobiomaterials by nanoindentation test. Contemp Clin Dent 2016;7(2):209-215

30 Khoroushi M, Shirban F, Doustfateme S, Kaveh S. Effect of three nanobiomaterials on the surface roughness of bleached enamel. Contemp Clin Dent 2015;6(4):466-470

31 Attin T, Schmidlin PR, Wegehaupt F, Wiegand A. Influence of study design on the impact of bleaching agents on dental enamel microhardness: a review. Dent Mater 2009;25(2):143-157

32 Efeoglu N, Wood D, Efeoglu C. Microcomputerised tomography evaluation of $10 \%$ carbamide peroxide applied to enamel. J Dent 2005;33(7):561-567

33 Li Y, Greenwall L. Safety issues of tooth whitening using peroxide-based materials. Br Dent J 2013;215(1):29-34

34 Alves EA, Alves FKA, Campos EdeJ, Mathias P. Susceptibility to carieslike lesions after dental bleaching with different techniques. Quintessence Int 2007;38(7):e404-e409

35 Potočnik I, Kosec L, Gašperšic D. Effect of $10 \%$ carbamide peroxide bleaching gel on enamel microhardness, microstructure, and mineral content. J Endod 2000;26(4):203-206 